\title{
Fuentes iconográficas y método iconológico en el Palacio de Riquelme
}

\author{
Antonio Aguayo Cobo \\ Universidad de Cádiz \\ antonioaguay076@gmail.com
}

El matrimonio del veinticuatro de Jerez don Hernán Riquel, con su sobrina doña Inés Riquelme dio lugar a una de las mayores fortunas del momento, pues a los quinientos mil maravedís que aportó el marido, su esposa como dote sumó otros setecientos mil, a los que habría que añadir los treinta mil ducados heredados por doña Inés de su padre, don Fernando Riquel (Moreno de Guerra, 1932: 23) -se produce así una auténtica endogamia familiar encaminada a consolidar una fortuna considerable con el fin de fundar un mayorazgo que se hará efectivo en 1560 en la cabeza de su primogénito Bartolomé-. Semejante fortuna exigía la construcción de un palacio, acorde al prestigio de la familia, que fuese exponente y espejo de la fortuna de sus dueños. Con este fin se contrata al maestro portugués, afincado en Jerez, Fernando Álvarez, que habría de dotar al palacio ya existente en la céntrica Plaza del Mercado, ubicada en la collación de San Mateo y centro neurálgico de la ciudad en ese momento, de una monumental fachada, acorde a la fortuna y prestigio de la familia.

Se concibe la fachada como un emblema, cuyo complejo mensaje moral, de profundo contenido humanista, habría de aportar legitimidad a la pretendida nobleza de la familia, negada por una parte de la rancia nobleza de sangre jerezana, durante tanto tiempo litigada, no siendo hasta algunos años después, cuando es reconocida por la Real Chancillería de Granada a su hijo Manuel, en 1572.

El contrato suscrito entre D. Fernando Riquel y el maestro albañil Fernando Álvarez el 11 de septiembre de 1542 (Guzmán y Orellana 2001: 71-73) aporta toda una serie de datos sumamente esclarecedores a la hora de analizar la fachada del palacio. Es interesante el dato de que el maestro albañil, Fernando Álvarez no puede firmar el documento, por declararse analfabeto, por lo que ha de firmar en su nombre el escribano Juan de Porras. Creemos que este dato permi- te excluir por completo al maestro como posible autor del programa iconográfico, cuya autoría corresponde, con toda probabilidad, al comitente y dueño del palacio, don Fernando Riquel. 1) El primer punto es la declaración explícita de que la mencionada fachada ha de hacerse en «las casas de mi morada, con una ventana encima de la dicha portada", con lo cual queda atestiguada la previa existencia de un palacio, y que la obra que se contrata está destinada a dotar dicha morada de la nobleza y majestuosidad que le correspondería a la fortuna y nobleza del dueño, y del que carece en ese momento. Para ello se toma como modelo el palacio de alguien de indiscutible prestigio como es D. Francisco de Siles, escribano público del crimen. 2) Dicho modelo ha de ser modificado "conforme a la muestra e traça questa en un papel que dello tenemos fecho». 3) Las modificaciones están muy claras, tales como el lugar que ha de ocupar el escudo en el centro del dintel, o la elevación de las columnas. 4) La utilización de columnas pareadas. 5) La modificación de la iconografía, sustituyendo los niños con bastones por salvajes con mazas. 6) La representación de cuatro bustos, dos masculinos y dos femeninos, sobre las columnas y 7) La utilización de varias medallas en las jambas, flanqueando la puerta de entrada.

Todo ello expresa claramente que, aunque no se explicite en el texto del contrato, el dueño de la casa tiene in mente, perfectamente claro, el programa que se propone desarrollar en la fachada, y que ha de transmitir un mensaje moral, acorde a la demandada hidalguía del matrimonio. No se nombra, por considerarlo innecesario para el contrato, el contenido de las medallas o de los bustos a los que se alude, a pesar de que la identidad de los representados en los tondos debió de considerarla de tal importancia que no dudó en hacer inscribir sus nombres alrededor de los mismos. Del mismo modo se omite el mencionar los relieves de 
los trabajos de Hércules, situados sobre las columnas pareadas, al igual que los animales, en forma de grutescos, que acompañan los bustos del dintel, e incluso los relieves del cuerpo superior, donde se encuentra perfectamente identificables los relieves del unicornio y la doncella. A pesar de los silencios, lo que resulta indudable es que cuando menciona los cuatro bustos que han de situarse sobre las columnas, el comitente conoce que los representados son los dioses y diosas clásicos: Minerva, Marte, Venus y Vulcano, al igual que es conocedor de las identidades de las medallas, aunque no los mencione expresamente (Aguayo, 2003: 17).

Cada una de las figuras, de los medallones, de los grutescos, de los relieves, están pensados, están concebidos, para ocupar un lugar determinado, ya que cada una de las imágenes posee un valor semántico, un simbolismo preciso, que conforman un mensaje moral muy pensado y meditado, encaminado a mostrar unos valores que avalen la hidalguía del matrimonio Riquelme. La Concordia marital se erige como eje vertebrador del complejo programa iconográfico, capaz de unir y lograr la perfección de los vicios o imperfecciones que genera la naturaleza en el hombre y la mujer tomados de manera aislada, pero que al unirse pueden lograr la virtud necesaria para la salvación de la pareja.

Si en el hombre el orgullo y la ira son sus cualidades determinantes, simbolizados por el lobo, la lujuria es lo que define fundamentalmente el carácter femenino, ejemplificado por medio de la pantera, como se aprecia en el dintel, centrado todo en el escudo de la familia Riquelme, tal como exige en el contrato el comitente, D. Fernando Riquel. La fachada se divide en dos partes perfectamente diferenciadas, masculina y femenina, divididas por el eje central que supone el escudo y la alegoría de la Concordia marital. Hay una contraposición entre ambos lados, entre la virginidad y castidad que es lo que se pide, valora y exige en la mujer y el valor, la fuerza y el orgullo, característica del lado masculino. Los distintos personajes representados en los tondos, los relieves, o las medallas sirven como exempla, como modelo de lo que se está tratando de mostrar. Así, el relieve de Hércules y el león de Nemea ilustra el valor del héroe, al tiempo que su furor, en tanto que el episodio del rapto de Deyanira por el centauro Neso, ejemplifica la idea de lujuria, no sólo por parte del raptor, sino también las consecuencias para Hércules, abrasado en su propia camisa, empapada en la sangre del centauro, culminando así su venganza, al tiempo que muestra las consecuencias de la lujuria. Nabucodonosor se contrapone a Constantino y Camila a Rómulo y Remo.

Del mismo modo, los relieves que adornan la corona de Nabucodonosor y el casco de Camila, son el ejemplo gráfico más evidente de los peligros de los respectivos vicios. El orgullo del rey Nabucodonosor es castigado condenándolo a vivir y comer como los cerdos. Por su parte, la virgen Camila muestra en su casco la lucha de centauros y lapitas, como claro ejemplo de la lucha de la razón y la civilización frente a la lujuria salvaje de los centauros [1]. La conclusión, como no podía ser de otra forma, es el vicio derrotado por la virtud, ejemplificado por las cabezas de los monstruos aherrojados, en tanto que a ambos lados se muestra el unicornio, el más fiero de los animales, humillado y arrodillado ante la virginidad de la joven.

Recientemente se ha localizado la fuente iconográfica que pudo haber servido de modelo para el relieve de la virgen Camila, basado en un supuesto retrato de Alejandro Magno, que figura en el libro de Andrea Fulvio, Illustrium Imagines, publicado en Roma en 1517, en cuyo casco se representa, al igual que en el de Camila, la lucha de centauros y lapitas (Moreno, 2017). Este hallazgo lleva al autor a escribir: «Con la identificación de la fuente iconográfica de este tondo se puede descartar el discurso iconológico sugerido (Aguayo, 2003: 23) a partir de la citada escena representada en el casco de Camila Magna». Ante una aseveración tan contundente, a la par que gratuita, es preciso reflexionar acerca de lo que significa la aplicación y utilización del método iconológico aplicado al análisis de una determinada obra de arte. Para ello creemos que nada mejor que recordar las palabras del maestro Panofsky:

\footnotetext{
El historiador del arte tendrá que comprobar lo que él cree que es el significado intrínseco de la obra, o grupo de obras, a las que dedique su atención, contra lo que él crea que es el significado intrínseco de tantos documentos de civilización relacionados históricamente con aquella obra o grupo de obras, como pueda dominar: documentos que testifiquen sobre las tendencias políticas, poéticas, religiosas, filosóficas, y sociales de la personalidad, periodo o país que se están investigando (1972: 24).
}

Ya apuntamos en su momento que algunas de las medallas representadas en la fachada del palacio de Ri- 

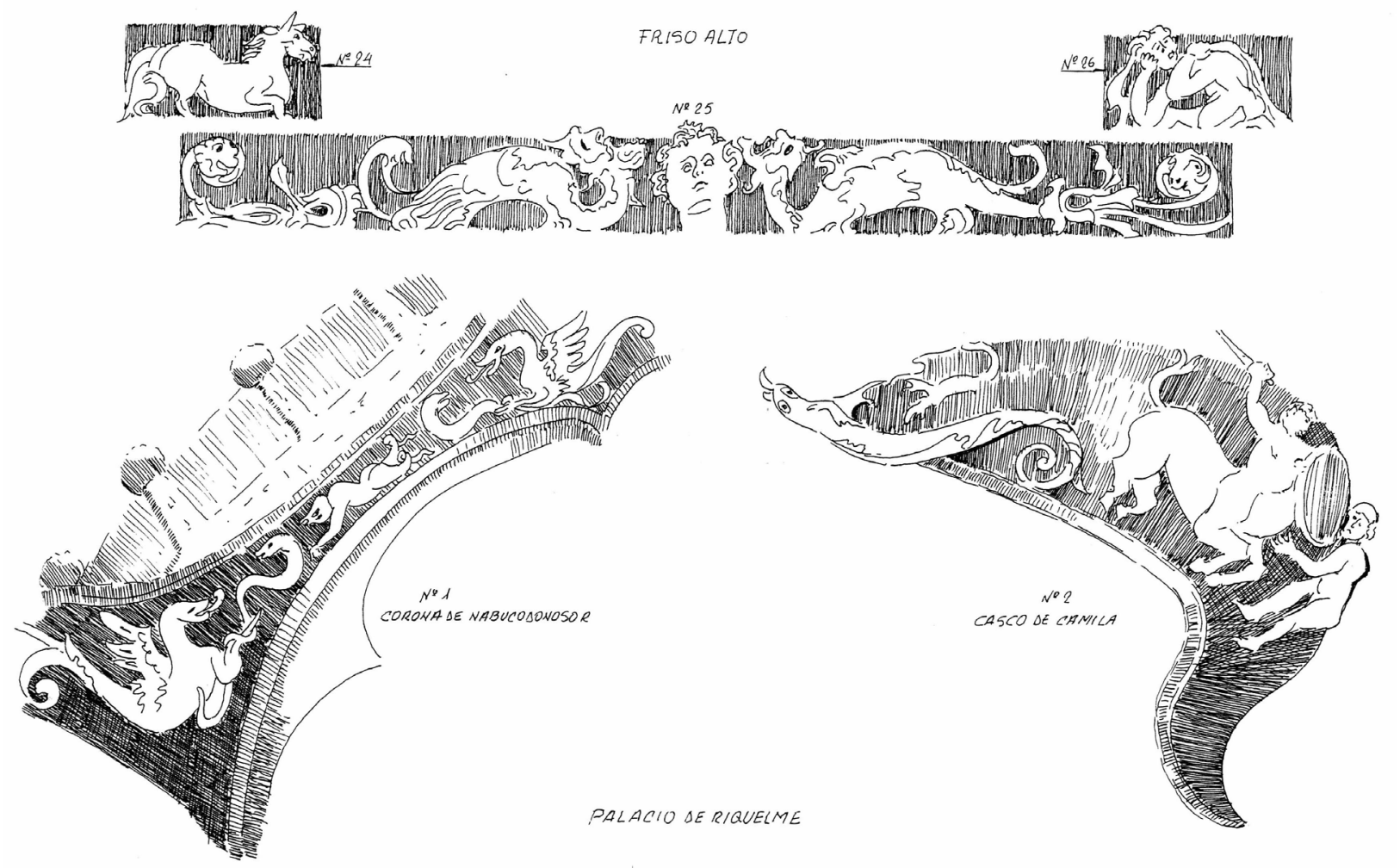

1. Relieves de la corona de Nabucodonosor y el casco de Camila (dibujo: Xoán Xosé Braxe)

quelme estaban tomadas de los relieves que adornan la fachada de la cartuja de Pavía (Aguayo, 2003: 14). Sin embargo, no fue este dato lo que nos pareció más significativo a la hora de realizar el análisis iconológico. Es evidente que los artistas del momento poseían toda una colección de estampas y grabados en los que inspirarse para la realización de los encargos. Hay que tener en cuenta que el concepto de originalidad no hay que verlo tal como se concibe en la actualidad. Por el contrario, lo necesario era mostrar que la obra poseía antecedentes, modelos en los que se inspira o que directamente copia -no hay más que ver el contrato anteriormente aludido, en el que el comitente D. Fernando Riquel exige que la fachada de su palacio se haga a imitación de la del escribano del crimen D. Fernando de Siles-. Lo realmente sorprendente es que se considere que el hallazgo de una fuente iconográfica pueda alterar el mensaje contenido en un programa iconográfico. Lo que realmente importa es el sentido que adquieren las imágenes en un contexto determinado, al dotárselas de un valor semántico. Las fuentes en las que se basa o se ha podido basar el autor, el comitente, a la hora de realizar un programa tan complejo como este son de muy distinto tipo, literarias, religiosas, filosóficas, o iconográficas. Sea como fuere, el hallazgo de esa fuente iconográfica no sólo no contradice la interpretación iconológica que hicimos en su día, sino que creemos que la ratifica. Lo que se copia en el jerezano palacio de Riquelme no es alguno de los ideales retratos de la reina Camila existentes en ese momento [2], sino que lo que realmente interesa es el casco en donde se representa la lucha de centauros y lapitas, de profundo y significado y simbolismo. Como imagen de Camila se adapta el rostro de ambigua belleza de Alejandro, invirtiendo su posición para adaptarse al medio y al marco, modificándolo en un rostro femenino, de gran belleza [3]. 


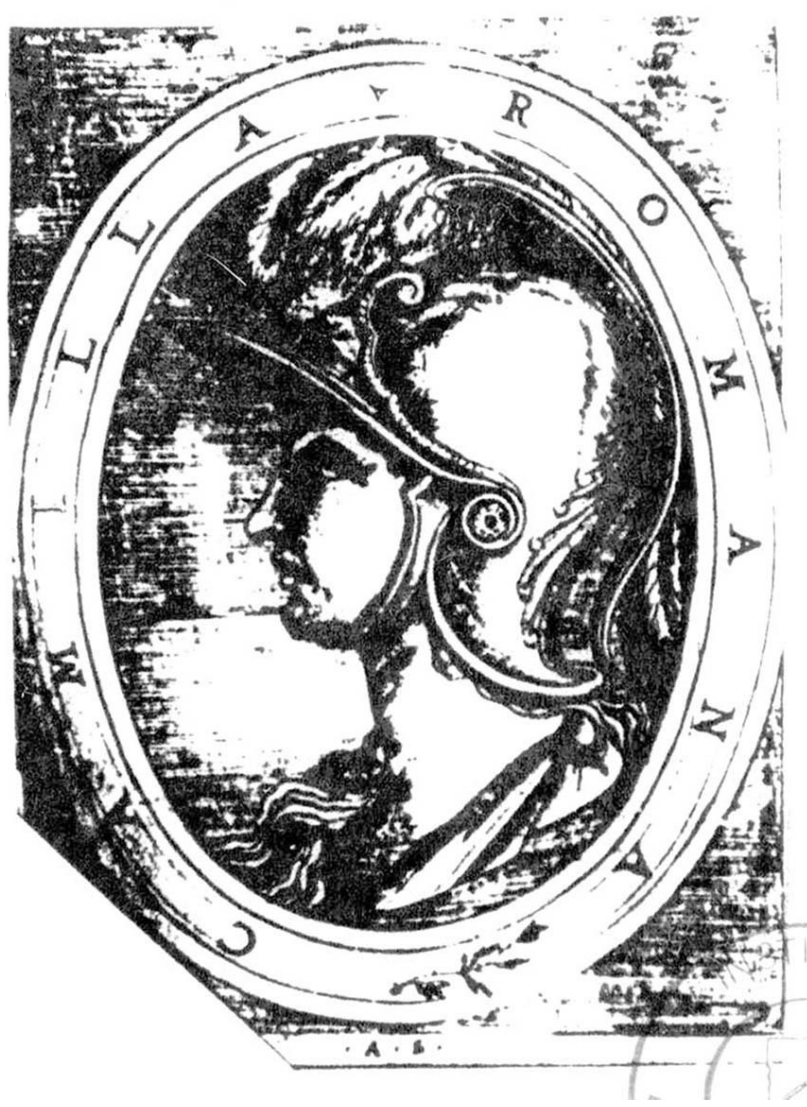

2. Antonio Salamanca: Camila Romana (1538-1563) Colección de El Escorial

Nos felicitamos por el hallazgo de la fuente iconográfica, ya que cuantos más datos se conozcan acerca de una determinada obra de arte más perfecto será nuestro análisis de dicha obra, al tiempo que es gratificante para el investigador que lo realiza. En este caso, el hallazgo de la citada fuente iconográfica creemos que ha servido para corroborar un programa cuyos elementos icónicos están perfectamente ensamblados, de manera coherente y racional, adquiriendo cada uno de ellos un valor semántico dentro del complejo programa moral que quiere transmitir, no sólo una idea de virtud, sino más bien una concepción virtuosa de la vida que los haga partícipes del estatus de nobleza que por algunos les es negado.

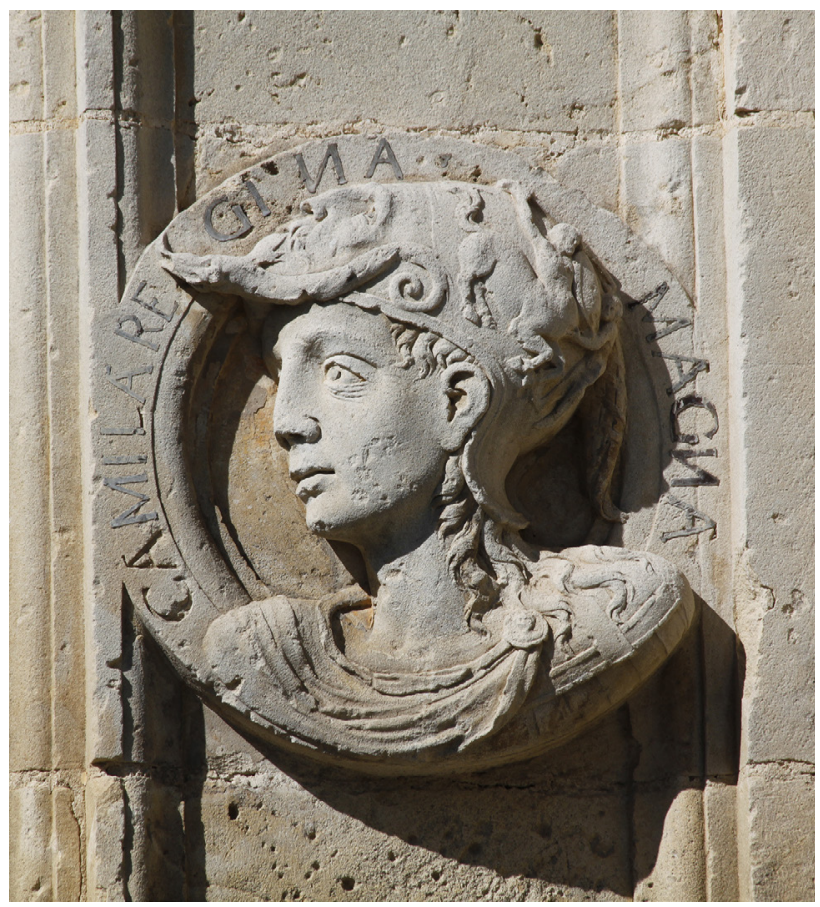

3. Camila Regina Magna. Palacio de Riquelme (fotografía: Antonio Aguayo)

Lo que creemos que no se puede ni se debe confundir son dos conceptos diferentes, como son los de iconografía e iconología. En el primero es importante lo representado, e incluso puede ser interesante su fuente iconográfica, ya sea literaria o gráfica. El análisis iconológico va mucho más allá. Las imágenes hay que verlas como un lenguaje que hay que comprender en un sentido simbólico, alegórico, independientemente de donde se hayan copiado o cuales sean su fuentes inmediatas o últimas. El humanismo supo utilizar las figuras clásicas adaptándolas a las exigencias de la moral cristiana. La interpretación de dichas imágenes es la tarea que compete al historiador de arte, no debiendo quedarse en la simple descripción o filiación. Al comitente no le interesaba mostrar sus fuentes, nihil novum sub sole. Lo que pretendía era mostrar un programa que iba mucho más allá de la simple erudición. Era una cuestión social y de prestigio. Entenderlo de otra manera es no comprender el espíritu del arte y el momento que lo hizo posible. 


\section{Bibliografía}

AGUAYO COBO, Antonio (2003), «El Palacio de Riquelme: Interpretación iconológica», Revista de Historia de Jerez, n. 9, pp. 9-26.

GUZMÁN OLIVEROS, Natividad y ORELLANA GONZÁLEZ, Cristóbal (2001), «El Palacio renacentista de Riquelme (Jerez de la Frontera, 1542)", Revista de Historia de Jerez, n. ${ }^{\circ}$, pp. 49-75.

MORENO ARANA, Juan Antonio (2017), «lllustrium Imagines. (Roma 1517) de Andrea Fulvio, fuente de la decoración escultórica de la fachada del Palacio de Riquelme de Jerez de la Frontera (1542-1543)", Boletín de Arte, n. ${ }^{\circ} 38$, pp. 211-214.

MORENO DE GUERRA Y ALONSO, Juan (1932), Bandos en Jerez; los del puesto de abajo. Segunda parte. Ferraz, Madrid.

PANOFSKY, Erwin (1972), Estudios sobre iconología, Alianza, Madrid. 
